\title{
Estimation and optimization of flank wear and tool lifespan in finish turning of AISI 304 stainless steel using desirability function approach
}

\author{
Lakhdar Bouzid $^{\text {ab }}$, Sofiane Berkani ${ }^{\mathrm{a}}$, Mohamed Athmane Yallese ${ }^{\mathrm{a}}$, Frençois Girardin ${ }^{\mathrm{c}}$ and Tarek \\ Mabrouki $^{\mathrm{d}}$
}

${ }^{a}$ Mechanical Engineering Department, Mechanics and Structures Research Laboratory (LMS), May 8th 1945 University, P.O. Box 401, Guelma 24000, Algeria

${ }^{b}$ University of Larbi Ben M'Hidi, Oum el Bouaghi, Algeria

${ }^{c}$ Laboratoire Vibrations Acoustique, INSA-Lyon, 25 bis avenue Jean Capelle, F-69621 Villeurbanne Cedex, France

${ }^{d}$ University of Tunis El Manar, ENIT, Tunis, Tunisia

CH RON I C L E

\begin{tabular}{l} 
Article history: \\
Received May 12017 \\
Received in Revised Format \\
July 12017 \\
Accepted August 112017 \\
Available online \\
August 112017 \\
\hline Keywords: \\
Flank wear \\
Surface roughness \\
Lifespan \\
Modeling \\
DFA \\
Optimization
\end{tabular}

\section{Introduction}

The tool wear, especially the flank wear, is one of the most important aspects that affect lifespan and product quality in machining. It is a major form of tool wear in metal cutting, which adversely affects the dimensional accuracy and product quality, is the main hurdle in the wide implementation of coated carbide tools to machining of stainless steel in the industry. Practically the lifespan is evaluated by the measure of the flank wear. If it increases quickly, the lifespan becomes very short and vice versa. In finish turning, tool life is measured by the machining time taken by the same insert until the flank wear reaches its allowable limit of $0.3 \mathrm{~mm}$. Wear is an important technological parameter of control in the machining process. It is the background for the evaluation of the tool life and surface quality (Yallese et

* Corresponding author Tel.: (+213) 773996958; Fax: (+213) 37215850

E-mail: issam.bouzid@yahoo.com (L. Bouzid)

(C) 2018 Growing Science Ltd. All rights reserved. doi: $10.5267 /$ j.ijiec.2017.8.002 
al., 2008; Uvaraja \& Natarajan, 2012; Çaydas, 2010). Therefore, development of a reliable flank wear progression model will be extremely valuable. Significant efforts have been devoted by several researchers in understanding and modeling the tool wear progression, wear mechanisms, tool lifespan and surface quality in metal cutting. In recent years, a significant emphasis has been placed in the development of predictive models in metal cutting. Analytical models are easy to implement and can give much more insight about the physical behavior in metal cutting. Kramer (1986) developed a model for prediction of the wear rates of coated tools in high-speed machining of steel. The abrasive wear and the chemical dissolution were considered as dominant wear mechanisms. Singh and Rao (2010) developed flank wear prediction model of ceramic inserts in hard turning. Flank wear rate was modeled considering abrasion, adhesion, and diffusion as dominant wear mechanisms. Normal load/force incurred on the flank face was modeled using experimental results. However, increase in the normal load with the progress in flank wear was not considered in the model. It is widely reported that cutting forces influence more with the progress in flank wear, which appeared as one of the most promising techniques for monitoring tool wear. Singh and Vajpayee (1980) developed a flank wear model considering abrasion as the dominant wear mechanism. Yallese et al. (2009) have shown that for the 100Cr6 steel, the machined surface roughness is a function of the local damage form and the wear profile of a CBN tool. When augmenting cutting speed tool wear increases and leads directly to the degradation of the surface quality. In spite of the evolution of flank wear up to the allowable limit $V B=0.3 \mathrm{~mm}$, arithmetic roughness $R a$ did not exceed $0.55 \mu \mathrm{m}$. A relation between $V B$ and $R a$ in the form $R a=k \cdot e^{\beta(V B)}$ is proposed. Coefficients $k$ and $\beta$ vary within the ranges of $0.204-0.258$ and $1.67-2.90$, respectively. It permits the follow-up of the tool wear.

A common problem in product or process design is the selection of design variable setting which meets a required specification of quality characteristics. For this purpose, among global approximation approaches, the response surface methodology (RSM) has recently attracted the most attention since it has performed well in comparison to other approaches (Garcia et al., 1981; Smith, 1973). RSM consists of the following three steps: (1) data gathering, (2) modeling, and (3) optimization (Aouici et al., 2014). Neşeli et al. (2011) applied response surface methodology (RSM) to optimize the effect of tool geometry parameters on surface roughness in hard turning of AISI 1040 with P25 tool. Yallese et al. (2009) found that a cutting speed of $120 \mathrm{~m} / \mathrm{min}$ is an optimal value for machining X200Cr12 using CBN7020. In an original work carried out by Çaydaş (2009), the effects of the cutting speed, feed rate, depth of cut, workpiece hardness, and cutting tool type on surface roughness, tool flank wear, and maximum toolchip interface temperature during an orthogonal hard turning of hardened/tempered AISI 4340 steels were investigated. Dureja et al. (2009) applied the response surface methodology (RSM) to investigate the effect of cutting parameters on flank wear and surface roughness in hard turning of AISI H1 1 steel with a coated-mixed ceramic tool. The study indicated that the flank wear is influenced principally by feed rate, depth of cut and workpiece hardness. When turning hardened 100Cr6, Banga and Abrão (2003) found that cutting speed is the most factor influencing tool lifespan. These authors have shown that PCBN cutting tools provide longer tool lifespan than both mixed and composite ceramics. A model built to evaluate the machinability of Hadfield steel using RMS and ANOVA techniques was presented by (Horng et al., 2008). The study revealed that the flank wear is influenced by the cutting speed while the interaction effect of the feed rate with the nose radius and the corner radius of the tool have statistical significance on obtained surface roughness.

The current study investigates the influence of cutting parameters (cutting speed, feed rate and cutting time, with a constant cutting depth $a p=0.15 \mathrm{~mm}$ ) in relation to flank wear $(V B)$, lifespan $(T)$ and surface roughness $(R a)$ on machinability. The processing conditions are turning of stainless steel (AISI 304) with CVD coated carbide tools using both response surface methodology (RSM) and ANOVA. This latter is a computational technique that enables the estimation of the relative contributions of each of the control factors to the overall measured response. In this work, only the significant parameters will be used to develop mathematical models using response surface methodology. The latter is a collection of mathematical and statistical techniques that are useful for the modeling and analysis of 
problems in which response of interest is influenced by several variables and the objective is to optimize the response.

\section{Experimental procedures}

\subsection{Material}

Straight turning operations were carried out on $100 \mathrm{~mm}$ diameter and $400 \mathrm{~mm}$ length bars made of AISI 304 stainless steel with the chemical specification given in Table 1. Machining operations were achieved on a $6.6 \mathrm{KW}$ power TOS TRENCIN model SN40 lathe.

Table 1

Chemical composition of AISI 304 steel ( $w t \%)$

\begin{tabular}{cccccccc}
\hline $\mathrm{C}$ & $\mathrm{Cr}$ & $\mathrm{Ni}$ & $\mathrm{Si}$ & $\mathrm{Mn}$ & $\mathrm{Mo}$ & $\mathrm{Fe}$ & Other components \\
\hline 0.02 & 16.91 & 7.69 & 0.33 & 1.44 & 0.41 & 72.10 & 1.1 \\
\hline
\end{tabular}

\subsection{Cutting tool and tool holder}

Cutting inserts used are " $\mathrm{Ti}(\mathrm{C}, \mathrm{N}) / \mathrm{Al}_{2} \mathrm{O}_{3} / \mathrm{TiN}$ " CVD coated carbide referenced as GC2015 (SNMG 1204-08-MF). The cutting inserts were clamped on a right-hand tool holder with designation PSBNR25x25M12. The geometry of the right-hand tool holder is characterized by the following angles: $\chi_{r}=+75^{\circ}, \lambda=-6^{\circ}, \gamma=-6^{\circ}$ and $\alpha=+6^{\circ}$.

\subsection{Measurement setup}

A roughness meter (2D) Surftest 201 Mitutoyo was employed to measure surface roughness $R a$. The length examined is $4 \mathrm{~mm}$ with a cut-off of $0.8 \mathrm{~mm}$ and the measured values of $R a$ are within the range $0.55-3.2 \mu \mathrm{m}$. Flank wear $V B$ is usually observed in the flank face of a cutting insert. Among the different forms of tool wear, flank wear is the important measure of the lifespan as it affects the surface quality of the workpiece. Long-term wear tests have been carried out through straight turning to evaluate CVD coated carbide tool flank wear for various cutting conditions. Flank wear is measured using a binocular microscope (Visuel Gage 250) equipped with (Visual Gage 2.2.0) software Fig. 1.

\subsection{Planning of experiments}

In order to develop the mathematical model based on RSM, two full factorials design $\left(3^{3}\right.$ and $\left.3^{2}\right)$ are adopted as the experimental design method. In the current study, cutting speed, feed rate and cutting time are identified as the factors which affect the responses such as surface roughness, flank wear and lifespan. Three levels are defined for each factor to investigate surface roughness and flank wear behavior. On the other hand, to investigate the lifespan behavior three levels are defined for two factors (cutting speed and feed rate) (Table 2).

Table 2

Attribution levels of cutting parameters

\begin{tabular}{|c|c|c|c|c|c|}
\hline \multirow{2}{*}{ Control parameters } & \multirow{2}{*}{ Unit } & \multirow{2}{*}{ Symbol } & \multicolumn{3}{|c|}{ Levels } \\
\hline & & & Level 1 & Level 2 & Level 3 \\
\hline \multicolumn{6}{|c|}{ Flank wear (VB) and surface roughness (Ra) } \\
\hline Cutting speed & $\mathrm{m} / \mathrm{min}$ & $V c$ & 280 & 330 & 400 \\
\hline Feed rate & $\mathrm{mm} / \mathrm{rev}$ & $f$ & 0.08 & 0.11 & 0.14 \\
\hline Cutting time & $\min$ & $t$ & 4 & 10 & 16 \\
\hline \multicolumn{6}{|l|}{ Lifespan $(T)$} \\
\hline Cutting speed & $\mathrm{m} / \mathrm{min}$ & $V c$ & 280 & 330 & 400 \\
\hline Feed rate & $\mathrm{mm} / \mathrm{rev}$ & $f$ & 0.08 & 0.11 & 0.14 \\
\hline
\end{tabular}




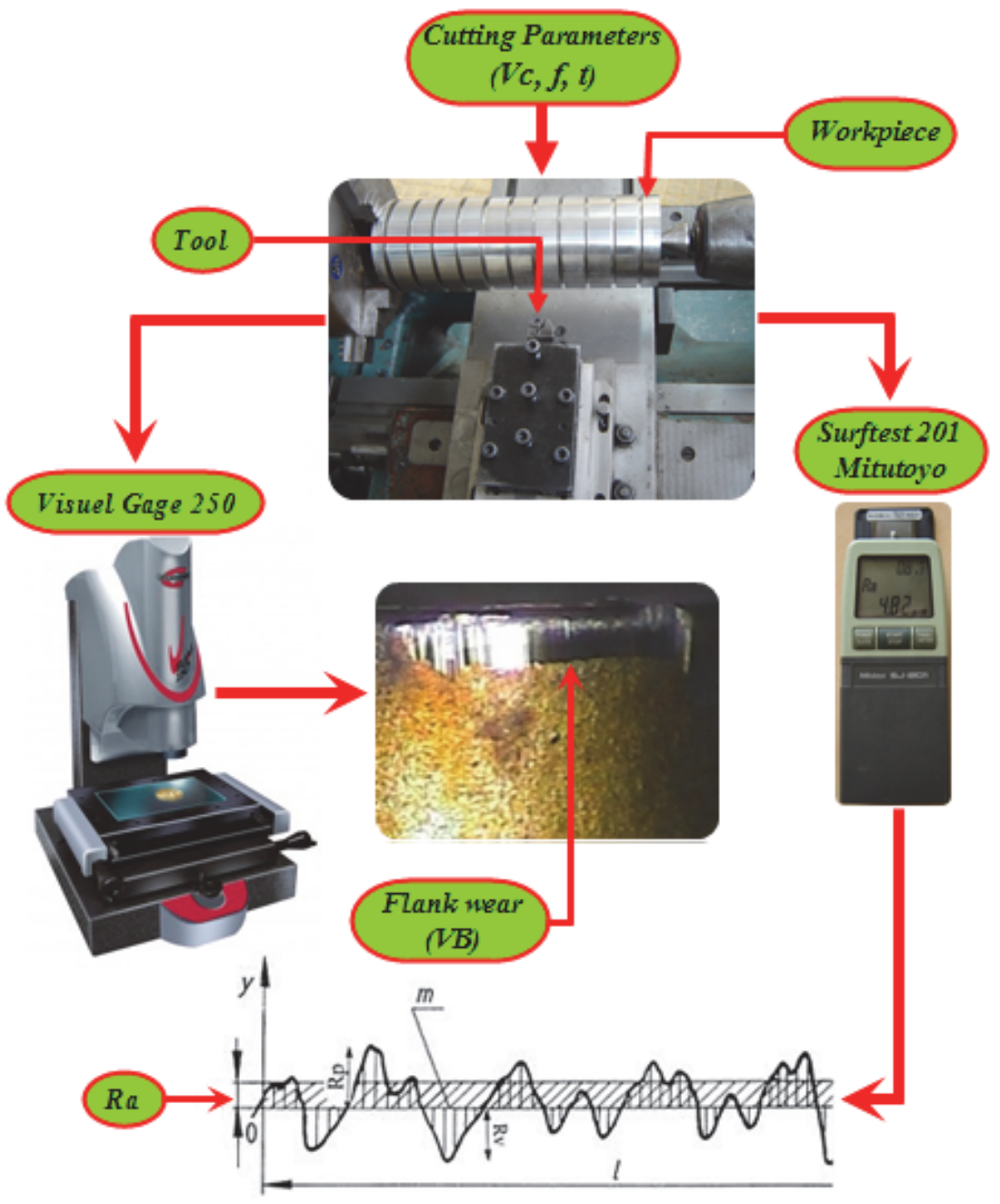

Fig. 1. Illustration of measured surface roughness and flank wear

\subsection{RSM-technique}

In the present investigation, the second-order RSM-based mathematical models for flank wear $(V B)$, surface roughness $(R a)$ and lifespan $(T)$ were developed with cutting speed $(V c)$, feed rate $(f)$, and cutting time $(t)$ as the process parameters. RSM technic is recognized as a statistical technique based on simple multiple regressions. Using this technique, the effect of two or more factors on quality criteria can be investigated and optimum values could be obtained. The results are expressed in $3 \mathrm{D}$ series or counter map. In the procedure of analysis, the approximation of response $(Y)$ was proposed using the fitted second-order polynomial regression model which is commonly called the quadratic model. The quadratic model of $Y$ can be written as follow Eq. (1):

$$
Y=a_{0}+\sum_{i=1}^{3} a_{i} X_{i}+\sum_{i=1}^{3} a_{i i} X_{i}^{2}+\sum_{i<j} \sum_{i j} X_{i} X_{j}+\varepsilon
$$

where $a_{0}$ is constant, $a_{i}, a_{i i}$ and $a_{i j}$ represent respectively the coefficients of linear, quadratic and cross product terms. $X_{i}$ reveals the coded variables that correspond to the studied machining parameters such as cutting speed $(V c)$, feed rate $(f)$ and cutting time $(t)$, and $\varepsilon$ is a random experimental error. The analysis of variance (ANOVA) has been applied to check the adequacy of the developed machinability models (Bouzid et al., 2015; Berkani et al. 2015; Zahia et al. 2015; Keblouti et al. 2017). The ANOVA table consists of sum of squares and degrees of freedom. The sum of squares is performed into contributions from the polynomial model and the experimental value and was calculated by the following Eq. (2): 


$$
S S_{f}=\frac{N}{N_{n f}} \sum_{i=1}^{N_{n f}}\left(\bar{y}_{i}-\bar{y}\right)^{2}
$$

The mean square is the ratio of sum of squares to degrees of freedom was calculated by the following Eq. (3):

$$
M s_{i}=\frac{S S_{f}}{d f_{i}}
$$

The F-value is the ratio of mean square of regression model to the mean square of the experimental error was calculated by the following Eq. (4):

$$
F_{i}=\frac{M s_{i}}{M s_{e}}
$$

This analysis was out for a $5 \%$ significance level, i.e., for a $95 \%$ confidence level. The last column of the tables shows the percentage of each factor contribution (Cont. \%) on the total variation, then indicating the degree of influence on the result, was calculated by the following Eq. (5):

$$
\text { Cont. } \%=\frac{S S_{f}}{S S_{T}} \times 100
$$

\section{Results and discussion}

Table 3 and Table 4 show all the values of the response factors: flank wear $(V B)$, surface roughness $(R a)$ and lifespan $(T)$, and were made with the objective of analysing the influence of the cutting speed $(V c)$, feed rate $(f)$, and cutting time $(t)$ on the total variance of the results. The surface roughness was obtained in the range of $0.55-3.2 \mu \mathrm{m}$, flank wear and lifespan were obtained in the range of $0.025-0.51 \mathrm{~mm}$, and

\begin{tabular}{|c|c|c|c|c|c|}
\hline \multirow{2}{*}{ Run } & \multicolumn{3}{|c|}{ Factors } & \multicolumn{2}{|c|}{ Responses } \\
\hline & $V_{c, m} / \min$ & $f, \mathrm{~mm} / \mathrm{rev}$ & $t, \min$ & $R a, \mu m$ & $V B, m m$ \\
\hline 1 & 280 & 0.08 & 4 & 0.56 & 0.025 \\
\hline 2 & 280 & 0.08 & 10 & 0.61 & 0.050 \\
\hline 3 & 280 & 0.08 & 16 & 0.74 & 0.100 \\
\hline 4 & 280 & 0.11 & 4 & 0.81 & 0.030 \\
\hline 5 & 280 & 0.11 & 10 & 1.17 & 0.074 \\
\hline 6 & 280 & 0.11 & 16 & 1.25 & 0.110 \\
\hline 7 & 280 & 0.14 & 4 & 1.32 & 0.045 \\
\hline 8 & 280 & 0.14 & 10 & 1.34 & 0.069 \\
\hline 9 & 280 & 0.14 & 16 & 1.35 & 0.110 \\
\hline 10 & 330 & 0.08 & 4 & 0.55 & 0.040 \\
\hline 11 & 330 & 0.08 & 10 & 0.62 & 0.115 \\
\hline 12 & 330 & 0.08 & 16 & 0.80 & 0.190 \\
\hline 13 & 330 & 0.11 & 4 & 0.79 & 0.060 \\
\hline 14 & 330 & 0.11 & 10 & 1.21 & 0.135 \\
\hline 15 & 330 & 0.11 & 16 & 1.60 & 0.170 \\
\hline 16 & 330 & 0.14 & 4 & 1.31 & 0.06 \\
\hline 17 & 330 & 0.14 & 10 & 1.47 & 0.185 \\
\hline 18 & 330 & 0.14 & 16 & 1.92 & 0.350 \\
\hline 19 & 400 & 0.08 & 4 & 0.80 & 0.050 \\
\hline 20 & 400 & 0.08 & 10 & 1.24 & 0.200 \\
\hline 21 & 400 & 0.08 & 16 & 1.99 & 0.410 \\
\hline 22 & 400 & 0.11 & 4 & 0.87 & 0.065 \\
\hline 23 & 400 & 0.11 & 10 & 1.55 & 0.290 \\
\hline 24 & 400 & 0.11 & 16 & 2.95 & 0.460 \\
\hline 25 & 400 & 0.14 & 4 & 1.16 & 0.070 \\
\hline 26 & 400 & 0.14 & 10 & 1.70 & 0.300 \\
\hline 27 & 400 & 0.14 & 16 & 3.20 & 0.510 \\
\hline
\end{tabular}
10-44 min, respectively.

Table 3

Experimental results for surface roughness and flank wear 
Table 4

Experimental results for lifespan

\begin{tabular}{cccc}
\hline \multirow{2}{*}{ un } & \multicolumn{2}{c}{ Factors } & \multicolumn{2}{c}{ Response } \\
\cline { 2 - 4 } & $V c, \mathrm{~m} / \mathrm{min}$ & $f, \mathrm{~mm} / \mathrm{rev}$ & 44 \\
\hline 1 & 280 & 0.08 & 42 \\
3 & 280 & 0.11 & 39 \\
4 & 280 & 0.14 & 27 \\
5 & 330 & 0.08 & 20 \\
6 & 330 & 0.11 & 15 \\
7 & 330 & 0.14 & 15 \\
9 & 400 & 0.08 & 11 \\
\end{tabular}

\subsection{ANOVA results}

Table 5 shows the results of ANOVA analysis for flank wear surface roughness and lifespan. In addition, the same Table 5 shows the degrees of freedom, sum of square, mean of square, F-value and P-value.

Table 5

ANOVA for response surface quadratic models

\begin{tabular}{|c|c|c|c|c|c|c|c|}
\hline Source & $e \quad d f$ & $S S$ & $M s$ & $F$ & $P$ & Cont, \% & Remarques \\
\hline \multicolumn{8}{|c|}{ a) Flank wear $(V B)$} \\
\hline Model & 9 & 0.49 & 0.05 & 65.46 & $<0.0001$ & 97.2 & Significant \\
\hline$V c$ & 1 & 0.17 & 0.17 & 203.66 & $<0.0001$ & 33.6 & Significant \\
\hline$f$ & 1 & 0.02 & 0.02 & 18.91 & 0.0004 & 3.12 & Significant \\
\hline$t$ & 1 & 0.23 & 0.23 & 279.92 & $<0.0001$ & 46.18 & Significant \\
\hline$V c \times f$ & 1 & 0.00 & 0.00 & 2.50 & 0.1326 & 0.41 & Not Significant \\
\hline$V c \times t$ & 1 & 0.08 & 0.08 & 98.26 & $<0.0001$ & 16.21 & Significant \\
\hline$f \times t$ & 1 & 0.00 & 0.00 & 4.44 & 0.0503 & 0.73 & Significant \\
\hline$V c^{2}$ & 1 & 0.00 & 0.00 & 0.10 & 0.7539 & 0.02 & Not Significant \\
\hline$f^{2}$ & 1 & 0.00 & 0.00 & 0.19 & 0.6723 & 0.03 & Not Significant \\
\hline$t^{2}$ & 1 & 0.00 & 0.00 & 0.01 & 0.9294 & 0 & Not Significant \\
\hline Residual & 17 & 0.01 & 0.00 & & & & \\
\hline Total & 26 & 0.50 & & & & & \\
\hline \multicolumn{8}{|c|}{ Surface roughness $(R a)$} \\
\hline Model & 9 & 10.51 & 1.17 & 31.75 & $<0.0001$ & 94.34 & Significant \\
\hline$V_{c}$ & 1 & 2.21 & 2.21 & 60.14 & $<0.0001$ & 19.84 & Significant \\
\hline$f$ & 1 & 2.59 & 2.59 & 70.52 & $<0.0001$ & 23.25 & Significant \\
\hline$t$ & 1 & 3.56 & 3.56 & 96.88 & $<0.0001$ & 31.96 & Significant \\
\hline$V c \times f$ & 1 & $1.7 .10^{-3}$ & $1.7 .10^{-3}$ & 0.046 & 0.8319 & 0.02 & Not Significant \\
\hline$V c \times t$ & 1 & 1.91 & 1.91 & 51.85 & $<0.0001$ & 17.15 & Significant \\
\hline$f \times t$ & 1 & 0.094 & 0.094 & 2.55 & 0.129 & 0.84 & Not Significant \\
\hline$V c^{2}$ & 1 & 0.17 & 0.17 & 4.55 & 0.0479 & 1.53 & Significant \\
\hline$f^{2}$ & 1 & 0.055 & 0.055 & 1.49 & 0.2389 & 0.49 & Not Significant \\
\hline$t^{2}$ & 1 & 0.086 & 0.086 & 2.33 & 0.1455 & 0.77 & Not Significant \\
\hline Residual & 17 & 0.63 & 0.037 & & & & \\
\hline Total & 26 & 11.14 & & & & & \\
\hline \multicolumn{8}{|c|}{ Lifespan $(T)$} \\
\hline Model & 5 & 1477.93 & 295.59 & 50.30 & 0.0043 & 98.82 & Significant \\
\hline$V c$ & 1 & 1320.17 & 1320.17 & 224.67 & 0.0006 & 88.27 & Significant \\
\hline$f$ & 1 & 79.83 & 79.83 & 13.59 & 0.0346 & 5.34 & Significant \\
\hline$V c \times f$ & 1 & 0.15 & 0.15 & 0.03 & 0.8833 & 0.01 & Not Significant \\
\hline$V c^{2}$ & 1 & 147.89 & 147.89 & 25.17 & 0.0153 & 9.89 & Significant \\
\hline$f^{2}$ & 1 & 0.89 & 0.89 & 0.15 & 0.7233 & 0.06 & Not Significant \\
\hline Residual & 3 & 17.63 & 5.88 & & & & \\
\hline Total & 8 & 1495.56 & & & & & \\
\hline
\end{tabular}

The ration of contribution of different factors and their interactions were also presented. The main purpose was to analyse the influence of cutting speed $(V c)$, feed rate $(f)$, and cutting time $(t)$ on the total variance of the results. From the analysis of Table 5, it can be apparent seen that the cutting time $(t)$, cutting speed $(V c)$, interactions $(V c \times t, f \times t)$ and feed rate $(f)$ all have significant effect on the flank wear 
$(V B)$. But, the effect of cutting time is the most significant factor associated for flank wear with $46.18 \%$. The next largest factor influencing $V B$ is the cutting speed. Its contribution is $33.60 \%$ to the model. The interaction $(V c \times t)$ were less significant, while $(V c \times f)$ interaction and productions $\left(V c^{2}, f^{2}, t^{2}\right)$ were found to be negligible. However, the value of "P" in Table 5 for surface roughness $(R a)$ model is less than 0.05 which indicates that the model is significant, which is desirable as it indicates that the terms in the model have a significant effect on the response. In the same manner, the main effect of cutting time $(t)$, feed rate factor $(f)$, cutting speed $(V c)$, the interaction of cutting speed and cutting time $(V c \times t)$, and the product $\left(V c^{2}\right)$ are significant model terms. It can be seen that the cutting time $(t)$ is the most important factor affecting $R a$. Its contribution is $31.96 \%$. The second important factor affecting $R a$ is the feed rate, because its increase generates helicoid furrows, the result of tool shape and helicoid movement toolworkpiece. These furrows are deeper and broader as the feed rate increases. Its contribution is $23.25 \%$. The next factors influencing $R a$ are the cutting speed, the interaction $(V c \times t)$ and the product $\left(V c^{2}\right)$. Other model terms can be said to be not significant.

Finality, it can be apparently seen in Table 5 that the cutting speed factor (Cont. $\approx 88 \%$ ), the feed rate factor (Cont. $\approx 5 \%$ ) and the product $V c^{2}$ (Cont. $\approx 9.9 \%$ ) have statistical significance on the lifespan $(T)$, especially the cutting speed.

\subsection{Influential factors}

To better view the results of the analysis of variance, a Pareto graph is built (Fig. 2 a, b, and c). This figure ranks the cutting parameters and their interactions of their growing influence on the flank wear $(V B)$, surface roughness $(R a)$ and lifespan $(T)$. Effects are standardized (F-value) for a better comparison. If the $(\mathrm{F}$-value $)$ values are greater than $(\mathrm{F}$-table $=4.45)$ for $V B$ and $R a$; and greater than $(\mathrm{F}$-table $=10.13)$ for lifespan, the effects are significant. By cons, if the values of F-value are less than $(4.45 ; 10.13)$ the effects are not significant. The confidence interval chosen is $95 \%$.

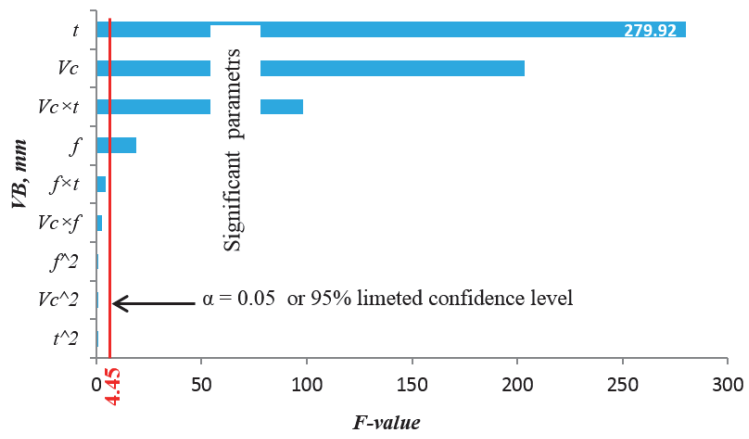

(a)

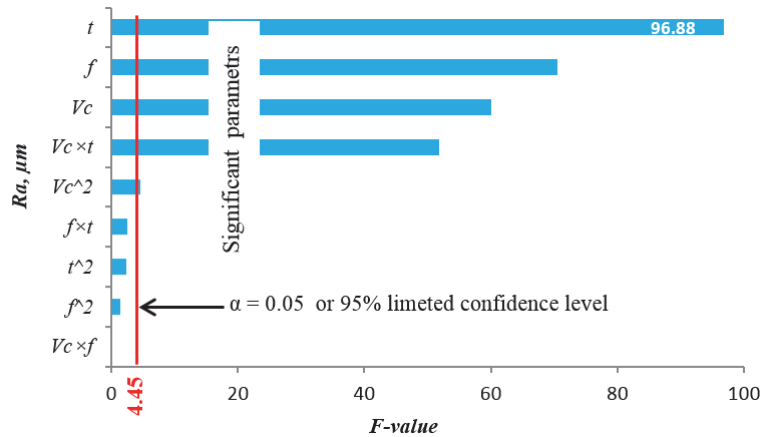

(b)

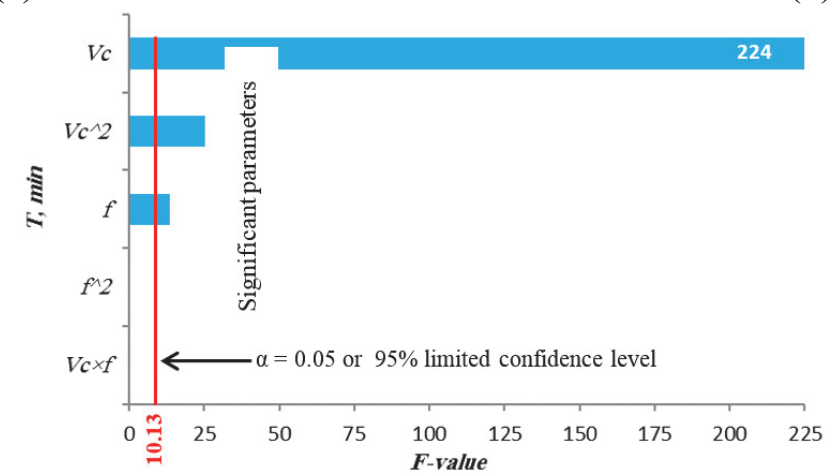

(c)

Fig. 2. Pareto graphs of: a) flank wear, b) surface roughness and c) lifespan 


\subsection{Regression equations}

The relationship between the inputs (cutting speed, feed rate and cutting time) and outputs ( $V B, R a$ and $T$ ) was modelled by quadratic regression equations. The different quadratic models obtained from statistical analysis can be used to predict the flank wear, surface roughness and lifespan according to the studied factors. The models and its determination coefficients obtained for different cutting phenomena are presented in Eqs. (6-8) respectively to (flank wear, surface roughness and lifespan).

$$
\begin{aligned}
V B= & 0.65-0.0021 V c-3.68 f-0.069 t+1.074 .10^{-6} V c^{2}+0.0072 V c \times f+0.00022 V c \times t \\
& +5.61 f \times f+0.097 f \times t+2.93 .10^{-5} t^{2} \\
R^{2}= & 97.20 \% \\
R a= & 5.68-0.037 V c+33.37 f-0.421 t+4.79 .10^{-5} V c^{2}-6.6 .10^{-3} V c \times f+0.0011 V c \times t \\
& -106.173 f^{2}+0.49 f \times t+0.0033 t^{2} \\
R^{2}= & 94.39 \% \\
T= & 413,26-1,94 V c-321,22 f+0,0024 V c^{2}+0,11 V c \times f+740,741 f^{2} \\
R^{2}= & 98.82 \%
\end{aligned}
$$

In order to reduce the models, only the significant parameters will be conserved.

$$
\begin{aligned}
V B & =0.19-6.59 .10^{-4} V c-0.011 f-0.069 t+2.27 .10^{-4} V c \times t+0.097222 f \times t \\
R^{2} & =96.73 \% \\
R a & =6.35-0.037 V c+12.703 f-0.3 t+1.102 .10^{-3} V c \times t+4.79 .10-5 V c^{2} \\
R^{2} & =92.27 \% \\
T & =400.77-1.92 V c-122.22 f-2.47 .10^{-3} V c^{2} \\
R^{2} & =98.75 \%
\end{aligned}
$$

\subsection{Models validation}

\subsubsection{Graphical Validation}

The above models can be used to predict flank wear, surface roughness and lifespan at the particular design points. The differences between measured and predicted responses are illustrated in Figs. (3-5). These figures indicate that the quadratic models are capable to representing the system under the given experimental domain.

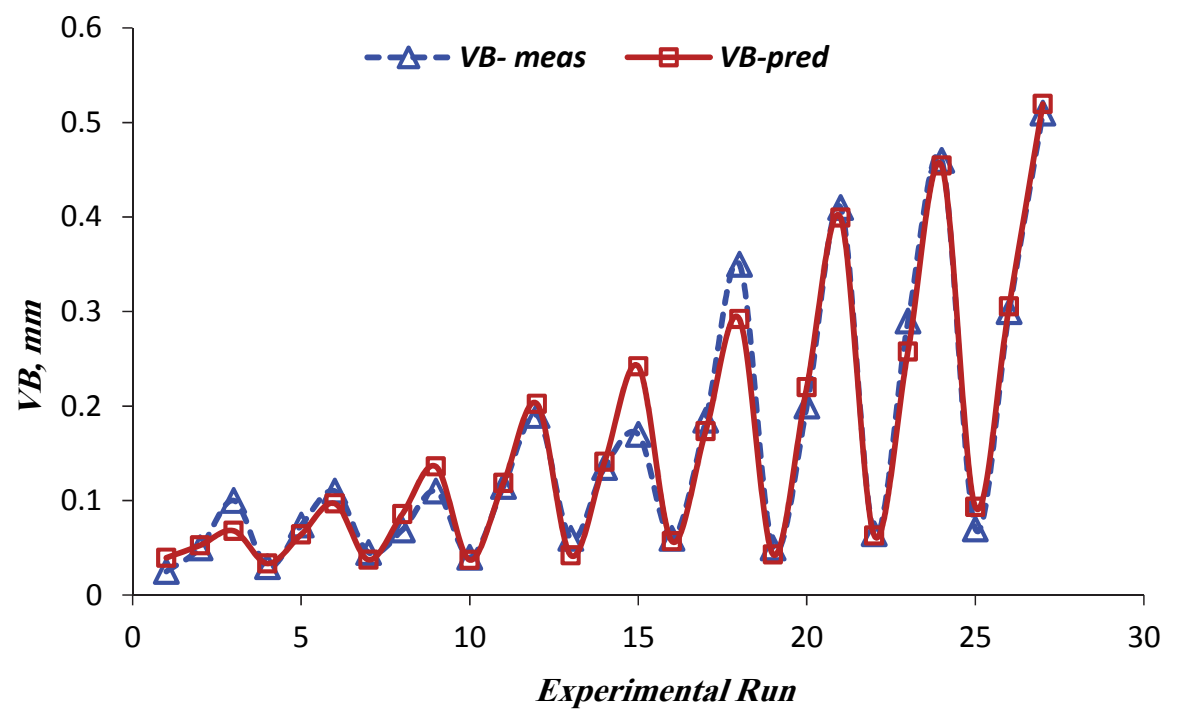

Fig. 3. Comparison between measured and predicted values for flank wear 


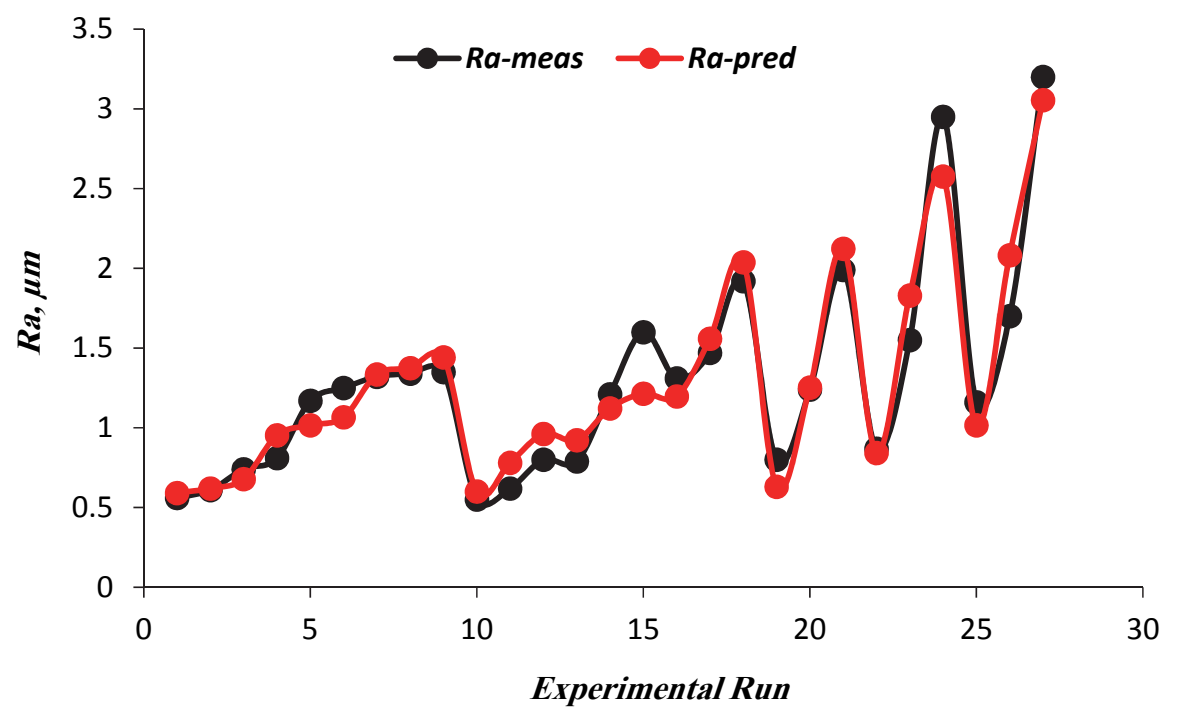

Fig. 4. Comparison between measured and predicted values for surface roughness

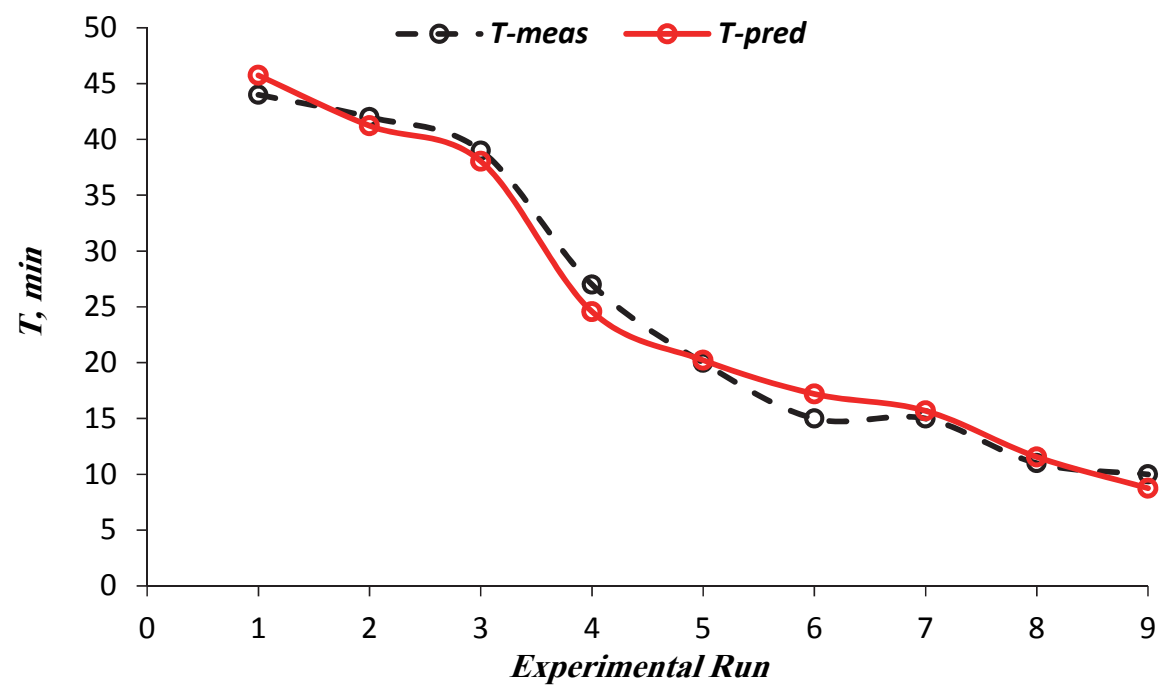

Fig. 5. Comparison between measured and predicted values for lifespan
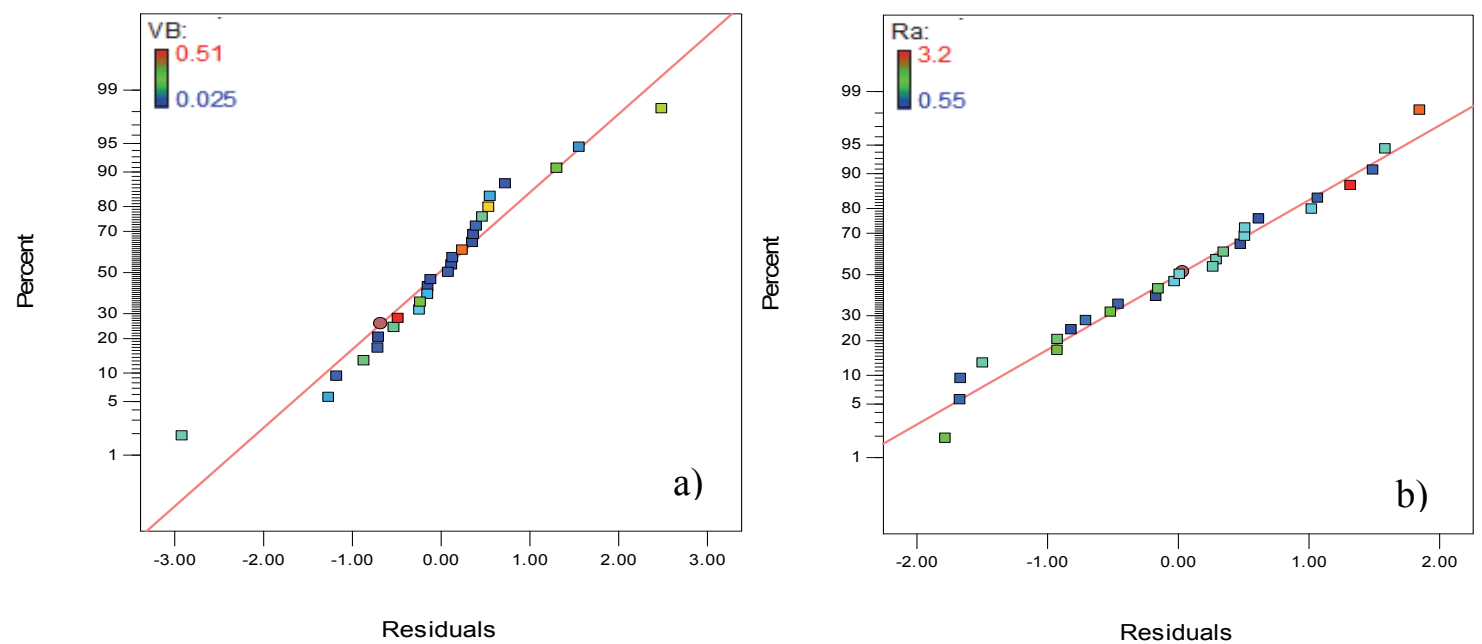


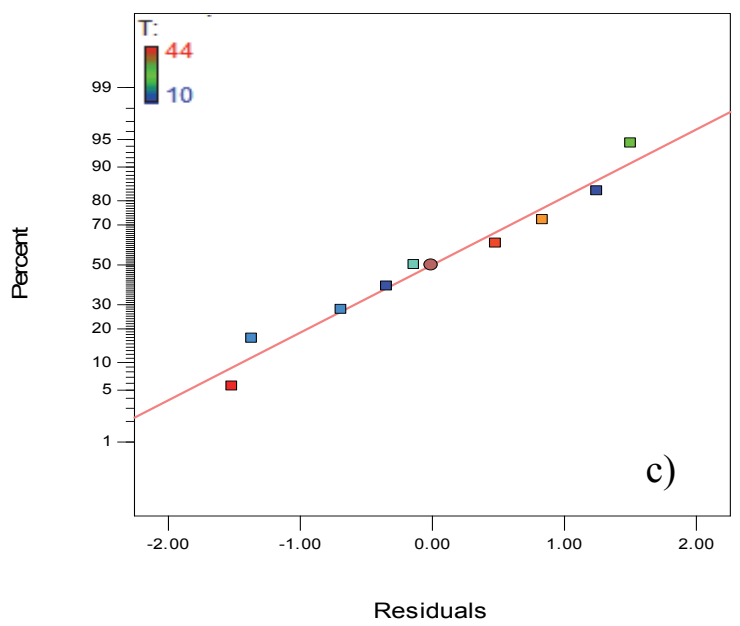

Fig. 6. Normal probability plots of predicted response for: a) flank wear, b) surface roughness and c) lifespan

The Anderson-Darling test and normal probability plots of predicted response for: surface roughness, flank wear and tool lifespan respectively, are presented in Figs.6 $(a, b, c)$. The data closely follows the straight line. The null hypothesis is that the data distribution law is normal and the alternative hypothesis is that it is non-normal. Using the P-value which is greater than alpha of 0.05 (level of significance), the null hypothesis cannot be rejected (i.e., the data don't follow a normal distribution). It implies that the models proposed are adequate.

\subsubsection{Mathematical validation}

The analysis of variance (ANOVA) was used to check the adequacy of developed models for a given confidence interval. The ANOVA table consists of sum of squares and degrees of freedom. In order to perform an ANOVA, the sum of squares is usually completed into contributions from regression model and residual error. As for this technique, if the calculated value of F-ratio of model is more than the standard tabulated value of table (F-table) for a given confidence interval, then the model is adequate within the confidence limit (Meddour et al., 2015; Muthukrishnan \& Davim, 2009; Elbah et al., 2013). The adequacy of developed mathematical models is presented in Tables 6 . The model accuracy $(\Delta)$ is commonly given by the following Eq.12 (Kaddeche et al., 2012):

$$
\Delta=\frac{100}{n} \sum_{i=1}^{n}\left|\frac{y_{i, \exp t}-y_{i, \text { pred }}}{y_{i, \text { pred }}}\right| \text {, }
$$

where $y_{i, \text { expt }}$ is the measured value of response corresponding to $i^{\text {th }}$ trial, $y_{i, p r e d}$ is the predicted value of response corresponding to $i^{\text {th }}$ trial and $n$ is the number of trials. Eqs. (9-11) are used to test the accuracy of the models using the experimental data. The prediction errors of these models are illustrated in Table 6 together with determination coefficients. It is concluded that the correlations are valid and can be used for predictions when turning AISI304 stainless steel.

Table. 6

ANOVA analysis, percent prediction error of the experimental data and $R^{2}$ values for $V B, R a$ and $T$

\begin{tabular}{|c|c|c|c|c|c|c|c|c|c|}
\hline \multirow[t]{2}{*}{ Responses } & \multicolumn{2}{|c|}{$S S$} & \multicolumn{2}{|c|}{ D. $f$} & \multicolumn{2}{|c|}{$M s$} & \multirow{2}{*}{$F$-test } & \multirow{2}{*}{ F-table } & \multirow[t]{2}{*}{$P$-value } \\
\hline & $M$ & $R$ & $M$ & $R$ & $M$ & $R$ & & & \\
\hline$V B$ & 0.48 & 0.014 & 9 & 17 & 0.054 & 0.0008 & 65.45 & 2.49 & $<0.0001$ \\
\hline$R a$ & 10.51 & 0.63 & 9 & 17 & 1.17 & 0.037 & 31.75 & 2.49 & $<0.0001$ \\
\hline$T$ & 1477.9 & 17.62 & 5 & 3 & 259.58 & 5.87 & 50.3 & 9.01 & 0.0043 \\
\hline \multicolumn{10}{|c|}{$\begin{array}{l}\text { M: model; } \boldsymbol{R}: \text { residual } \\
\quad \text { Responses }\end{array}$} \\
\hline$V B$ & \multicolumn{6}{|c|}{$\begin{array}{l}\% \text { Prediction error of the experimental data } \\
14.31\end{array}$} & \multicolumn{3}{|c|}{96.73} \\
\hline$R a$ & \multicolumn{6}{|c|}{11.51} & \multirow{2}{*}{\multicolumn{3}{|c|}{$\begin{array}{l}92.27 \\
98.75\end{array}$}} \\
\hline$T$ & \multicolumn{6}{|c|}{6.14} & & & \\
\hline
\end{tabular}




\subsection{Responses surface analysis}

\subsubsection{Flank wear}

Fig. 7 illustrates the evolution of the flank wear according to the cutting speed, cutting time and feed rate. It is found that tool wear increases with increasing effects of both cutting time and speed. It can be concluded that the cutting time exhibits maximum influence on flank wear. The maximum value of flank wear is found with height level of cutting time and cutting speed.
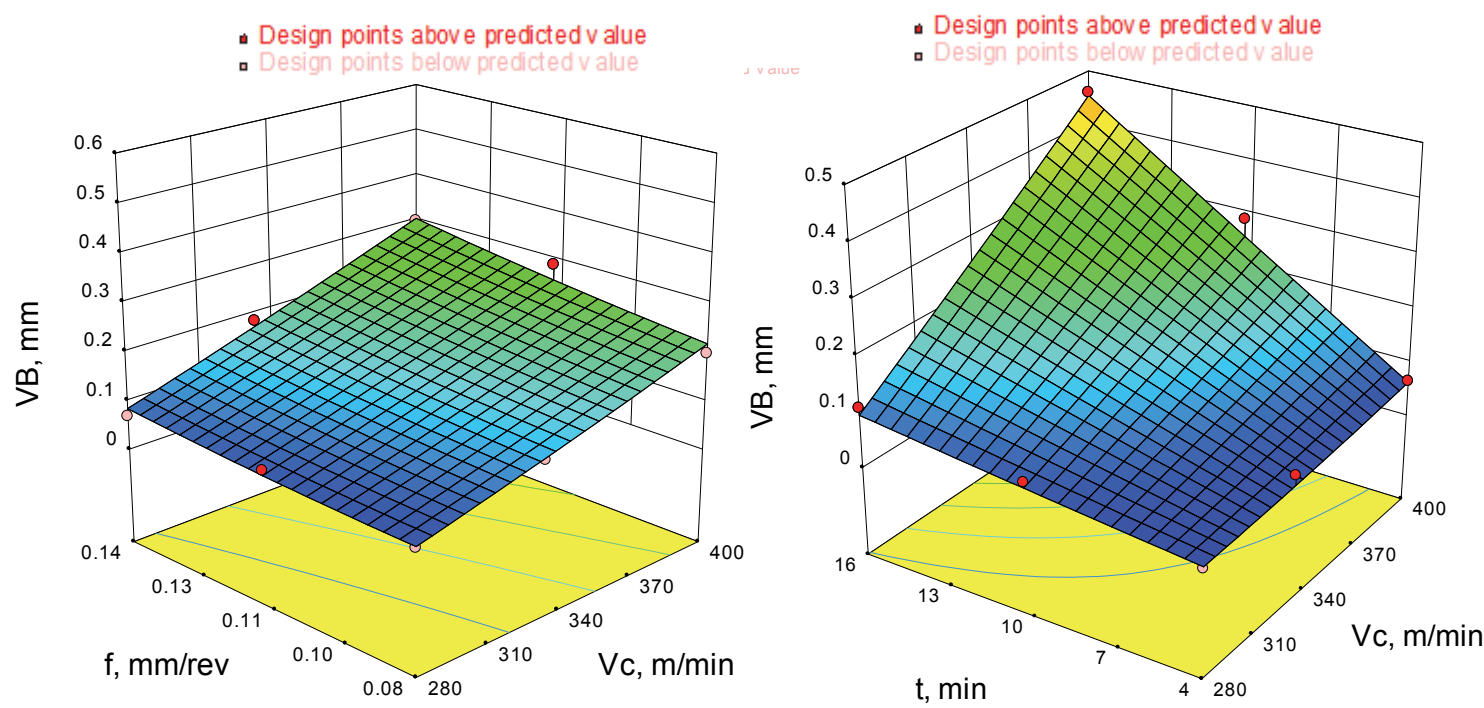

Fig. 7. Effect of cutting speed, feed rate and cutting time on flank wear

\subsubsection{Workpiece surface roughness}

The estimated response surface for the surface roughness in relation to the cutting parameters ( $V c, f$ and $t$ ) presented in (Fig. 8.) shows that the cutting speed had a significant influence on machined surface roughness.
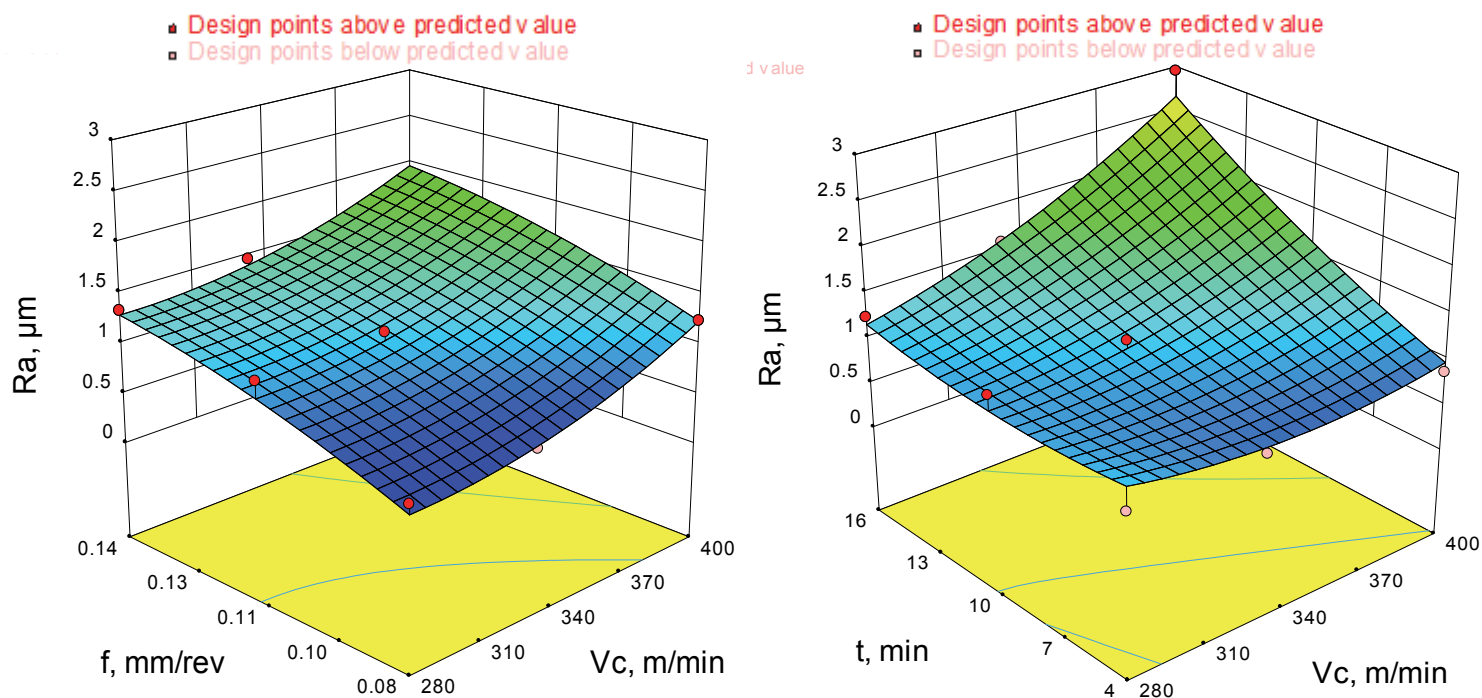

Fig. 8. Effect of cutting speed, feed rate and cutting time on surface roughness 
A high values of surface roughness noted in small value of cutting speed that can be explained by the presence of built up edge (Fig. 9.) on the surface due to the high ductility of austenitic stainless steel. With the increasing of cutting speed the surface roughness values decrease until a minimum value reached beyond which they increase. The decrease in surface roughness when increasing of cutting speed to $340 \mathrm{~m} / \mathrm{min}$ can be explained by the presence of micro-welds on machined surface due to high heat at cutting zone and the height of built-up-edge which lead to the breaking of BUE and carried away on the machined surface as seen in (Fig. 9). Further, increasing the cutting speed causes an increase in surface roughness because the cutting tool nose wear increases causing the poor surface finish (Ciftci, 2005). In the other hand, the roughness $(R a)$ tends to increase, considerably with increase in feed rate $(f)$ and cutting time $(t)$.
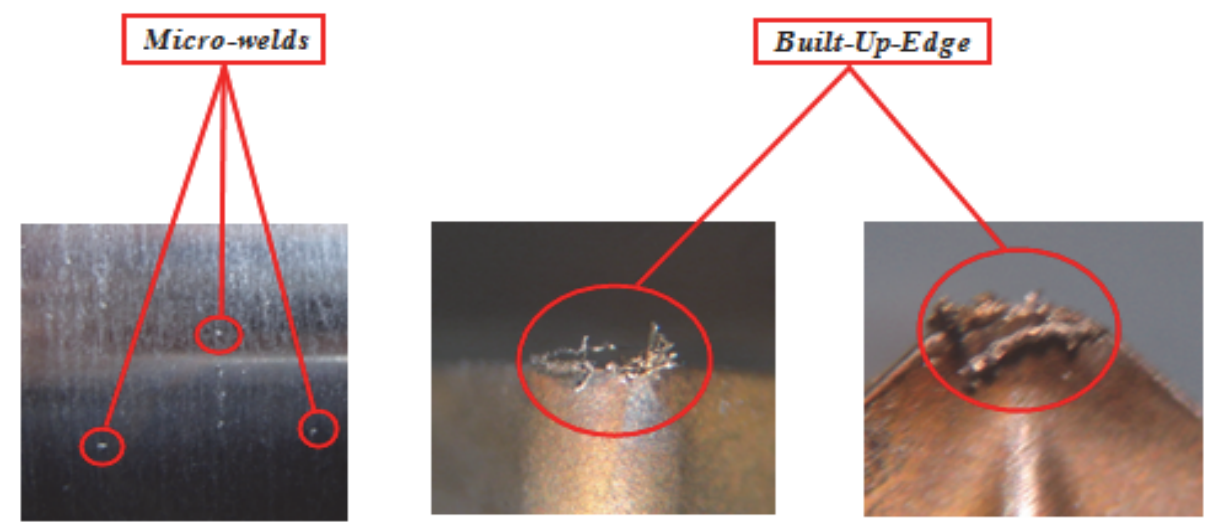

Fig. 9. Micro-Weld on machined surface and Built-Up Edge on cutting insert

\subsubsection{Lifespan}

The effect of feed rate $(f)$ and cutting speed $(V c)$ on the tool life $(T)$ is shown in Fig. 10. This figure displays that the value of tool life $(T)$ decrease with the increase of cutting speed and feed rate. The decrease is approximately $77.27 \%$ of $T$.

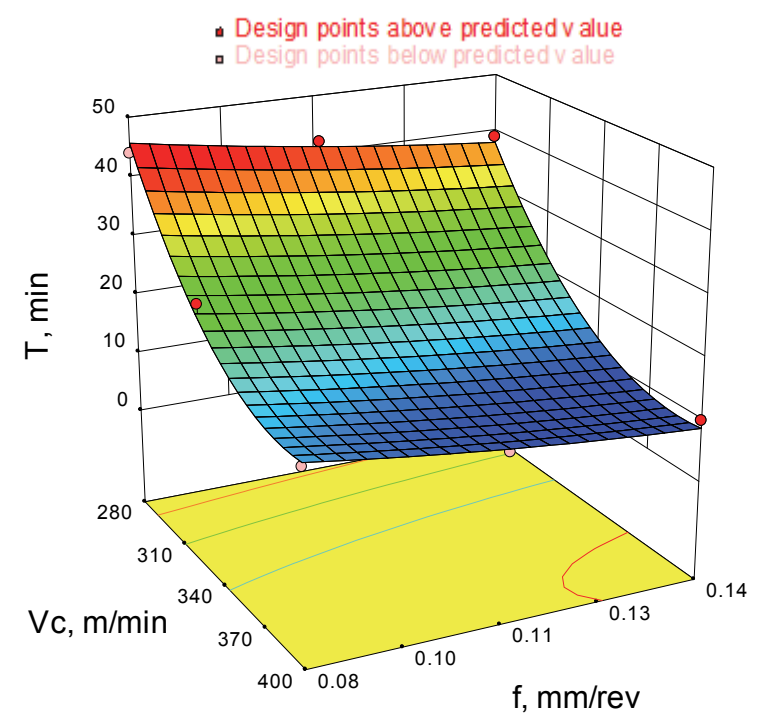

Fig. 10. Effect of cutting speed and feed rate on tool lifespan 


\subsection{Micrographs for flank wear VB of the GC2015 tool}

For the considered regime $(V c=280 \mathrm{~m} / \mathrm{min}, a p=0.15 \mathrm{~mm}$ and $f=0.08 \mathrm{~mm} / \mathrm{rev})$, flank wear $V B$ of the coated carbide tool GC2015 spreads regularly. Figure 11 shows the micrographs for $V B$ of GC2015 insert, its lifetime is $44 \mathrm{~min}$.

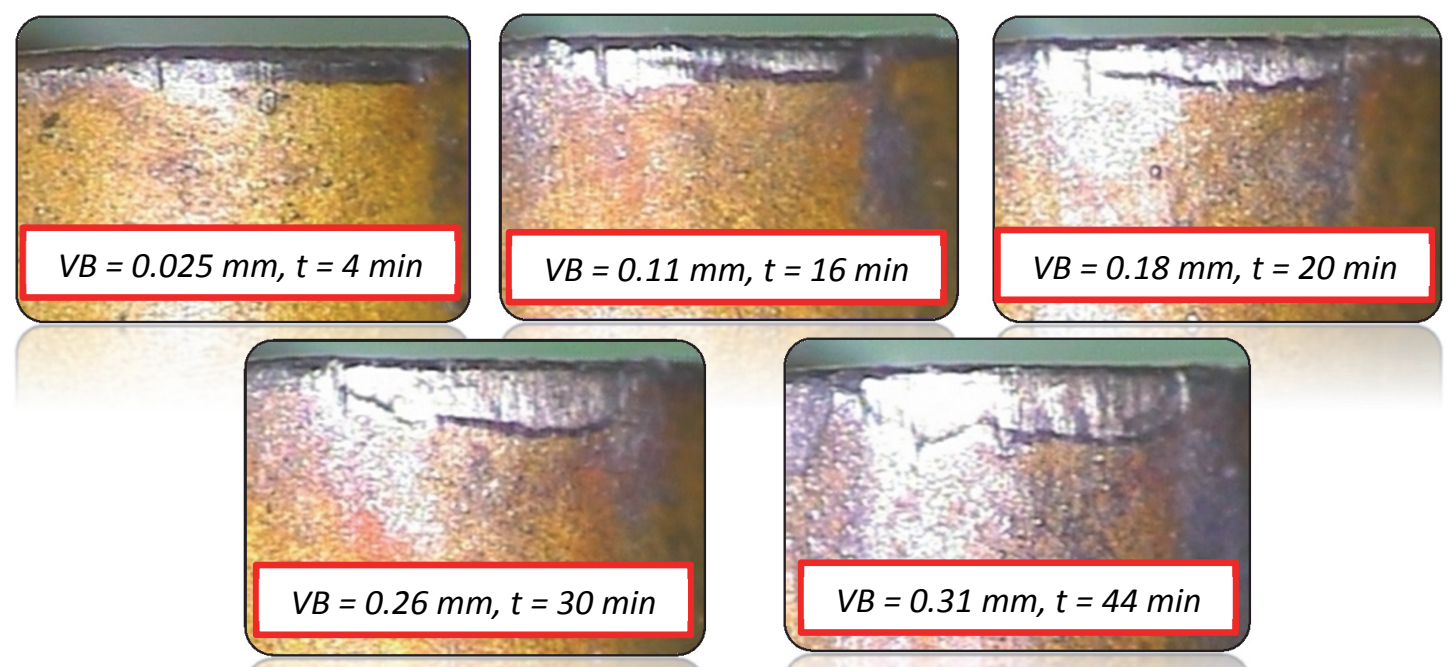

Fig. 11. Micrographs for $V B$ of GC2015 at $a p=0.15 \mathrm{~mm} ; f=0.08 \mathrm{~mm} / \mathrm{rev}$ and $V c=280 \mathrm{~m} / \mathrm{min}$

\section{Optimisation of machining performance using desirability function approach (DFA)}

The desirability function approach to simultaneously optimizing multiple responses was originally proposed by Derringer and Suich. Essentially, the approach is to translate the functions to a common scale $[0,1]$, combine them using the geometric mean and optimize the overall metric. DFA continue to be a commonly preferred method because it can solve multi response optimization problem by converting it into single response optimization problem which enable to sort the computational work (Bouzid et al., 2014). The concept of desirability function involves the translation of the responses from its individual desirability to scale of composite desirability (overall desirability function). The DFA optimization process is used to perform through the following steps:

Step 1: Define the independent input parameters of the experimental design and the desired responses $\left(y_{i}\right)$ to be optimized.

Step 2: Adopt an experimental design plan and conduct experiments for the designed parameter combinations.

Step 3: Calculate individual desirability $(d i)$ for each response $\left(y_{i}\right)$ using desirability functions.

- Larger-the-Better: For a goal to find a maximum, the individual desirability is shown as follows:

$d i=\left\{\begin{array}{ccc}0 & \text { if } & y_{i} \leq y_{i \min } \\ \frac{y_{i}-y_{i \min }}{y_{i \max }-y_{i \min }} & \text { if } & y_{i \min } \leq y_{i} \leq y_{i \max } \\ 1 & \text { if } & y_{i} \geq y_{i \min }\end{array}\right.$

- Smaller-the-Better: For a goal to find a minimum, the individual desirability is shown as follows: 


$$
d i=\left\{\begin{array}{ccc}
0 & \text { if } & y_{i} \leq y_{i \min } \\
\frac{y_{i \max }-y_{i}}{y_{i \max }-y_{i \min }} & \text { if } & y_{i \min } \leq y_{i} \leq y_{i \max } \\
1 & \text { if } & y_{i} \geq y_{i \min }
\end{array}\right.
$$

Step 4: Select the parameter combination that will maximize composite desirability $(D c)$, and determine the optimal parameter and its level combination based on the higher value of composite desirability $(D c)$.

$$
D c=\left(\prod_{i=1}^{p} d_{i}\right)^{\frac{1}{P}},
$$

where $(d i)$ is the individual desirability of the response $(i)$ and $(P)$ is the number of response in the measure. The desirability ranges from zero to one.

Step 5: The last step is performing ANOVA to indicate the most significant factor that affects the multiple performance characteristics.

\subsection{DFA optimization for $V B, R a$ and $T$}

During the optimisation process, the aim was to find the optimal values of machining parameters in order to produce the lowest flank wear, surface roughness $(V B$ and $R a$ ) and the highest lifespan $(T)$.

\section{Table 7}

\begin{tabular}{|c|c|c|c|c|c|c|c|}
\hline \multirow[t]{2}{*}{ Runs } & \multicolumn{3}{|c|}{ Factors } & \multicolumn{2}{|c|}{$\begin{array}{l}\text { Individual desirability } \\
\text { (di) }\end{array}$} & \multirow{2}{*}{$\begin{array}{c}\text { Composite desirability } \\
\qquad(D c) \\
(\%)\end{array}$} & \multirow{2}{*}{ Rank } \\
\hline & $V c(\mathrm{~m} / \mathrm{min})$ & $\begin{array}{c}f \\
(\mathrm{~mm} / \mathrm{rev})\end{array}$ & $\begin{array}{c}t \\
(\min )\end{array}$ & $\begin{array}{l}V B \\
(\%)\end{array}$ & $\begin{array}{l}R a \\
(\%)\end{array}$ & & \\
\hline 1 & 280 & 0.08 & 4 & 100 & 99.62 & 99.81 & 1 \\
\hline 2 & 280 & 0.08 & 10 & 94.85 & 97.74 & 96.28 & 3 \\
\hline 3 & 280 & 0.08 & 16 & 84.54 & 92.83 & 88.59 & 9 \\
\hline 4 & 280 & 0.11 & 4 & 98.97 & 90.19 & 94.48 & 4 \\
\hline 5 & 280 & 0.11 & 10 & 89.90 & 76.60 & 82.98 & 11 \\
\hline 6 & 280 & 0.11 & 16 & 82.47 & 73.58 & 77.90 & 15 \\
\hline 7 & 280 & 0.14 & 4 & 95.88 & 70.94 & 82.47 & 12 \\
\hline 8 & 280 & 0.14 & 10 & 90.93 & 70.19 & 79.89 & 14 \\
\hline 9 & 280 & 0.14 & 16 & 82.47 & 69.81 & 75.88 & 18 \\
\hline 10 & 330 & 0.08 & 4 & 96.91 & 100 & 98.44 & 2 \\
\hline 11 & 330 & 0.08 & 10 & 81.44 & 97.36 & 89.05 & 8 \\
\hline 12 & 330 & 0.08 & 16 & 65.98 & 90.57 & 77.30 & 16 \\
\hline 13 & 330 & 0.11 & 4 & 92.78 & 90.94 & 91.86 & 6 \\
\hline 14 & 330 & 0.11 & 10 & 77.32 & 75.09 & 76.20 & 17 \\
\hline 15 & 330 & 0.11 & 16 & 70.10 & 60.38 & 65.06 & 21 \\
\hline 16 & 330 & 0.14 & 4 & 92.78 & 71.32 & 81.35 & 13 \\
\hline 17 & 330 & 0.14 & 10 & 67.01 & 65.28 & 66.14 & 20 \\
\hline 18 & 330 & 0.14 & 16 & 32.99 & 48.30 & 39.92 & 24 \\
\hline 19 & 400 & 0.08 & 4 & 94.85 & 90.57 & 92.68 & 5 \\
\hline 20 & 400 & 0.08 & 10 & 63.92 & 73.96 & 68.76 & 19 \\
\hline 21 & 400 & 0.08 & 16 & 20.62 & 45.66 & 30.68 & 25 \\
\hline 22 & 400 & 0.11 & 4 & 91.75 & 87.92 & 89.82 & 7 \\
\hline 23 & 400 & 0.11 & 10 & 45.36 & 62.26 & 53.14 & 22 \\
\hline 24 & 400 & 0.11 & 16 & 10.31 & 9.43 & 9.86 & 26 \\
\hline 25 & 400 & 0.14 & 4 & 90.72 & 76.98 & 83.57 & 10 \\
\hline 26 & 400 & 0.14 & 10 & 43.30 & 56.60 & 49.51 & 23 \\
\hline 27 & 400 & 0.14 & 16 & 0 & 0 & 0 & 27 \\
\hline
\end{tabular}

Evaluated Individual desirability and composite desirability with their rank for $V B$ and $R a$ 
At first the evaluation of individual desirability $(d i)$ has been carried out for each response $\left(y_{i}\right)$ based on function Smaller-the-Better given in Eq. (13), which is used for minimization and Larger-theBetter as given in Eq. (14) used for maximization of response. Then, individual desirability (di) of each response characteristics are fluxed into the composite desirability $(D c)$ by using Eq. (15). Tables 7 and 8 show the evaluated individual desirability and composite desirability values for each of the experimental trials.

Table 8

Evaluated Individual desirability and composite desirability with their rank for lifespan $T$

\begin{tabular}{|c|c|c|c|c|}
\hline \multirow[b]{2}{*}{ Runs } & \multicolumn{2}{|c|}{ Factors } & \multirow{2}{*}{$\begin{array}{c}\text { Composite desirability } \\
(D c) \\
(\%) \\
\end{array}$} & \multirow[b]{2}{*}{ Rank } \\
\hline & $\begin{array}{c}V_{c} \\
m / \min \end{array}$ & $\begin{array}{c}f \\
\mathrm{~mm} / \mathrm{rev}\end{array}$ & & \\
\hline 1 & 280 & 0.08 & 100 & 1 \\
\hline 2 & 280 & 0.11 & 94.12 & 2 \\
\hline 3 & 280 & 0.14 & 85.29 & 3 \\
\hline 4 & 330 & 0.08 & 50 & 4 \\
\hline 5 & 330 & 0.11 & 29.41 & 5 \\
\hline 6 & 330 & 0.14 & 14.71 & 6 \\
\hline 7 & 400 & 0.08 & 14.71 & 7 \\
\hline 8 & 400 & 0.11 & 2.94 & 8 \\
\hline 9 & 400 & 0.14 & 0.00 & 9 \\
\hline
\end{tabular}

The composite desirability $(D c)$ has computed and the ranks are assigned to them in ascending order and it is found that the higher composite desirability value $(D c=99.81 \%$ for $V B$ and $R a ; D c=100 \%$ for $T$ ) obtained for the $1^{\text {st }}$ trial of the experiment and its corresponding cutting combination may be regarded as optimal combination which emphasize on being closer to the experimental results. To ensure the optimal combination of levels for various factors, Table 9 shows the response mean of average composite desirability function for each level and total mean of composite desirability is also evaluated. The maximum mean of composite desirability value of each level of the factors gives the optimum cutting combination which is $\left(V c_{1}-f_{1}-t_{1}\right)$ for $V B$ and $R a$, and $\left(V c_{1-} f_{l}\right)$ for $T$.

Table 9

Response table for Composite desirability $(D c)$

\begin{tabular}{|c|c|c|c|}
\hline \multicolumn{4}{|c|}{ Flank wear (VB) and Surface roughness (Ra) } \\
\hline \multirow{2}{*}{ Levels } & \multicolumn{3}{|c|}{ Average composite desirability } \\
\hline & $V c, \%$ & $f, \%$ & $t, \%$ \\
\hline 1 & 88.72 & 80.16 & 92.67 \\
\hline 2 & 75.62 & 72.20 & 73.04 \\
\hline 3 & 52.06 & 64.04 & 50.70 \\
\hline Max-Min & 36.66 & 16.12 & 41.97 \\
\hline Optimum Level & $V c_{1}$ & $f_{1}$ & $t_{1}$ \\
\hline \multicolumn{4}{|c|}{ Total mean of composite desirability $=72.13 \%$} \\
\hline \multicolumn{4}{|c|}{ Lifespan $(T)$} \\
\hline \multirow{2}{*}{ Levels } & \multicolumn{2}{|c|}{ Average composite desirability } & \\
\hline & $V c, \%$ & $f, \%$ & \\
\hline 1 & 93.14 & 54.9 & \\
\hline 2 & 31.37 & 42.16 & \\
\hline 3 & 5.88 & 33.33 & \\
\hline Max-Min & 87.25 & 21.57 & \\
\hline Optimum Level & $V c_{1}$ & $f_{1}$ & \\
\hline
\end{tabular}


The ANOVA results of composite desirability $(D c)$ depicts that the cutting time $(t)$ is the most significant parameter flowed by cutting speed $(V c)$ and feed rat $(f)$ on $V B$ and $R a$. Moreover, the cutting speed is the largest factor influencing tool lifespan $(T)$, its contribution is $(92.27 \%)$ as represented in the given Table 10 .

Table 10

ANOVA for composite desirability $(D c)$

\begin{tabular}{cccccccc}
\hline Source & $\boldsymbol{D F}$ & $\boldsymbol{S S}$ & $\boldsymbol{M S}$ & $\boldsymbol{F}$-value & P-value & Cont\% & Remarques \\
\hline Flank wear $(V B)$ & and Surface roughness $($ Ra) & & & & \\
\hline$V c$ & 1 & 0,517 & 0,517 & 31,262 & 0.000 & 29,37 & Significant \\
$f$ & 1 & 0,186 & 0,186 & 11,222 & 0,003 & 10,54 & Significant \\
$t$ & 1 & 0,678 & 0,678 & 40,945 & 0.000 & 38,47 & Significant \\
Error & 23 & 0,381 & 0,017 & & & & \\
Total & 26 & 1.761 & & & & & \\
\hline Lifespan $(T)$ & & & & & & & \\
\hline$V c$ & 1 & 1.194 & 1.194 & 237.402 & 0.0000 & 92.27 & Significant \\
$f$ & 1 & 0.070 & 0.070 & 13.877 & 0.0098 & 5.39 & Significant \\
Error & 6 & 0.030 & 0.005 & & & & \\
Total & 8 & 1.294 & & & & & \\
\hline
\end{tabular}

The contour plot of composite desirability $(D c)$ has been plotted between two most significant parameter by keeping the third term constant at first level $(f=0.08 \mathrm{~mm} / \mathrm{rev})$ in case of flank wear and surface roughness as shown in Fig 12 and between the parameters $(V c$ and $f$ ) in case of tool lifespan as shown in Fig 13 . The multiple response characteristic found maximum where $V c$ ranges from $280-345 \mathrm{~m} / \mathrm{min}$ with $t$ from $4-6.2 \mathrm{~min}$ for $V B$ and $R a$, and $V c$ from $280-297 \mathrm{~m} / \mathrm{min}$ with $f$ from $0.08-0.14 \mathrm{~mm} / \mathrm{rev}$ for $T$. This enclosed regions indicate the optimum zone for all responses where $V B$ and $R a$ will be minimized and $T$ will get maximized.

Composit desirability (Dc) for $\mathrm{VB}$ and $\mathrm{Ra}$

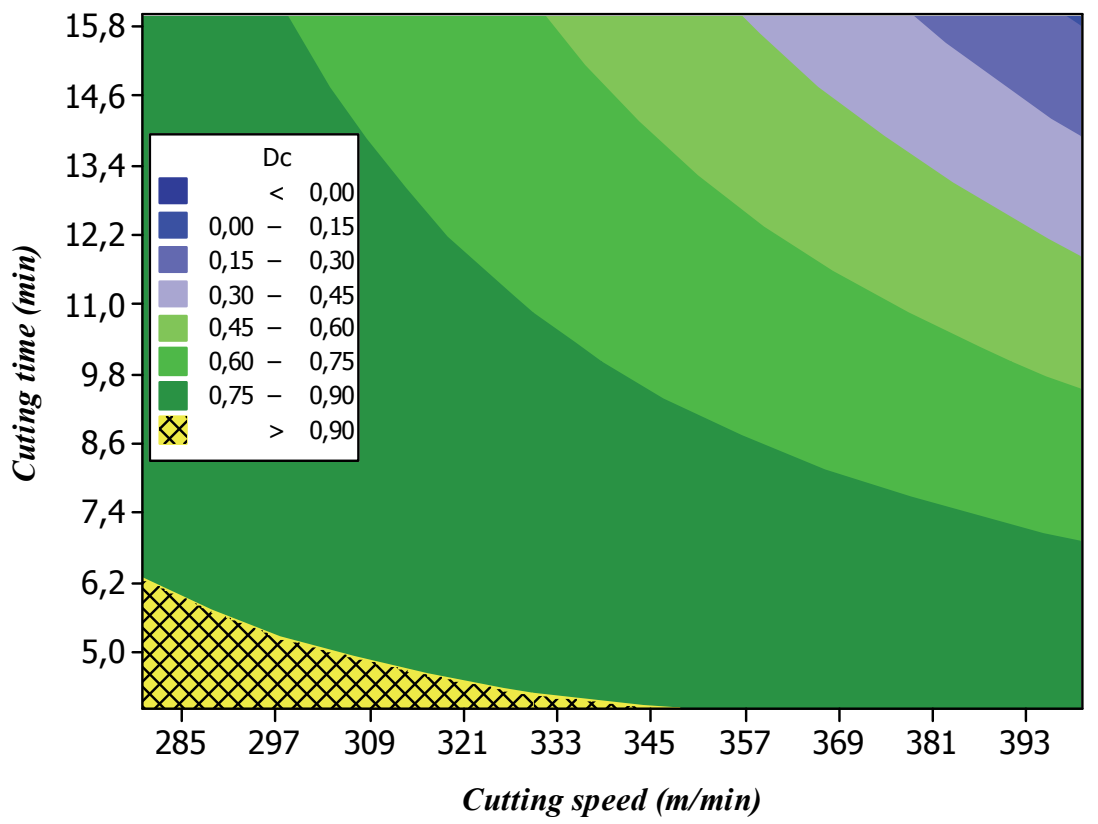

Fig. 12. Contour plot of composite desirability $(D c)$ for $V B$ and $R a$ 


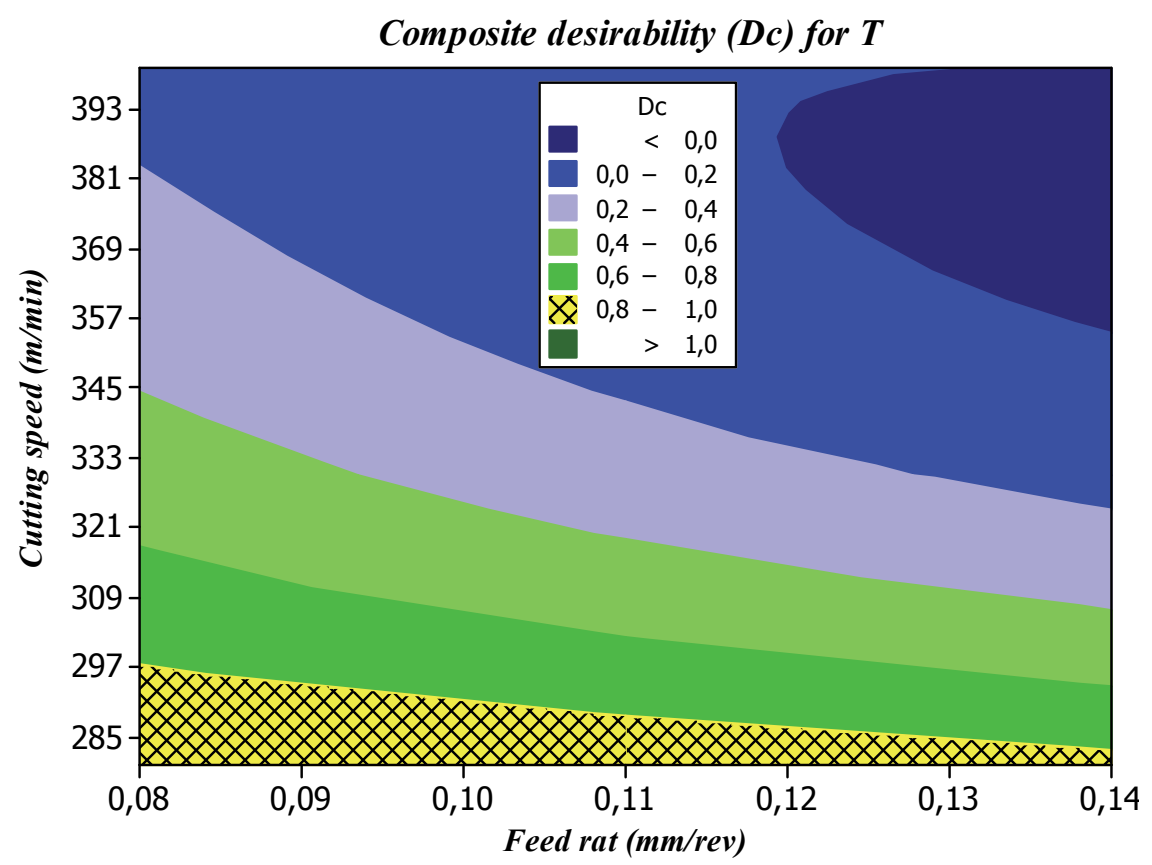

Fig. 13. Contour plot of composite desirability $(D c)$ for $T$

\subsection{Confirmation of results}

The predicted results based on the optimum level $\left(V c_{1}-f_{1}-t_{1}\right.$ for $V B, R a$ and $V c_{1-} f_{1}$ for $\left.T\right)$ are evaluated and comparisons between predicted values and associated experimental values have drawn in the terms of percentage error. The error percentage is within permissible limits, Table 11 shows the maximum percentage of error is $6.38 \%$.

Table 11

Confirmation results

\begin{tabular}{|c|c|c|c|}
\hline \multirow{2}{*}{ Responses } & Predicted & Experimental & Error \\
\hline & $\left(V c_{1}-f_{1}-t_{1}\right)$ & $\left(V c_{1}-f_{1}-t_{1}\right)$ & $(\%)$ \\
\hline$V B(\mathrm{~mm})$ & 0.0235 & 0.025 & 6.38 \\
\hline \multirow{2}{*}{$R a(\mu m)$} & 0.586 & 0.56 & 4.44 \\
\hline & $\left(V c_{1}-f_{l}\right)$ & $\left(V c_{1}-f_{l}\right)$ & \\
\hline$T(\min )$ & 45.72 & 44 & 3.76 \\
\hline
\end{tabular}

\section{Conclusion}

In this paper, the application of RSM for the turning of AISI 304 stainless steel with CVD coated carbide tool was presented. Mathematical models of flank wear $(V B)$, surface roughness $(R a)$ and lifespan $(T)$ evolutions according to the influence of machining parameters were investigated and optimal cutting parameters are determined through DFA optimization. The following conclusions were drawn:

1. The flank wear of CVD coated carbide tool increased with cutting speed and cutting time. The present study shows that a higher tool wear rate is noted at cutting speed $400 \mathrm{~m} / \mathrm{min}$ and cutting time of $16 \mathrm{~min}$. 
2. The flank wear is influenced principally by the cutting time, cutting speed and the interaction effect of cutting speed/cutting time with a contribution of $46.18 \%, 33.6 \%$ and $16.21 \%$, respectively.

3. The cutting time has a greater influence on the surface roughness $(31.96 \%)$ followed by feed rate (23.25\%), cutting speed (19.84\%) and the interaction cutting speed/cutting time (17.15\%).

4. Cutting speed influences lifespan ( $T$ ) of GC2015 more significantly than the feed rate.

5. The tool life of the coated carbide GC2015 is $44 \mathrm{~min}$.

6. The statistical models deduced define the degree of influence of each cutting regime element on flank wear and surface roughness. They can also be used for optimization of the cutting process.

7. Desirability functional approach (DFA) found very compatible to deal with multi-response optimization to obtain the optimal cutting conditions. The optimal cutting parameter combination for composite desirability reported as $V c_{1}-f_{1}-t_{1}$ which corresponds to cutting speed of $280 \mathrm{~m} / \mathrm{min}$, feed rate of $0.08 \mathrm{~mm} / \mathrm{rev}$ and cutting time of $4 \mathrm{~min}$ for $V B, R a$ and $V c_{1-} f_{1}$ which corresponds to $V_{c}=280 \mathrm{~m} / \mathrm{min}$ and $f=0.08 \mathrm{~mm} / \mathrm{rev}$ for lifespan.

8. From the confirmation results, it can be showed that better parameter combination for lifespan with $3.76 \%$ error followed by $4.44 \%$ error for surface roughness and $6.38 \%$ for $V B$ respectively.

\section{Acknowledgements}

This work was achieved in the laboratories LMS (University of Guelma Algeria) in collaboration with LaMCoS (CNRS, INSA-Lyon, France). The authors would like to thank the Algerian Ministry of Higher Education and Scientific Research (MESRS) and the Delegated Ministry for Scientific Research (MDRS) for granting financial support for CNEPRU Research Project, CODE: J0301520140021 (University 08 May 1945, Guelma).

\section{References}

Aouici, H., Bouchelaghem, H., Yallese, M. A., Elbah, M., \& Fnides, B. (2014). Machinability investigation in hard turning of AISI D3 cold work steel with ceramic tool using response surface methodology. The International Journal of Advanced Manufacturing Technology, 73(9-12), 17751788.

Bouzid, L., Yallese, M. A., Chaoui, K., Mabrouki, T., \& Boulanouar, L. (2015). Mathematical modeling for turning on AISI 420 stainless steel using surface response methodology. Proceedings of the Institution of Mechanical Engineers, Part B: Journal of Engineering Manufacture, 229(1), 45-61.

Bouzid, L., Yallese, M. A., Belhadi, S., Mabrouki, T., \& Boulanouar, L. (2014). RMS-based optimisation of surface roughness when turning AISI 420 stainless steel. International Journal of Materials and Product Technology, 49(4), 224-251.

Berkani, S., Yallese, M., Boulanouar, L., \& Mabrouki, T. (2015). Statistical analysis of AISI304 austenitic stainless steel machining using $\mathrm{Ti}(\mathrm{C}, \mathrm{N}) / \mathrm{Al} 2 \mathrm{O} 3 / \mathrm{TiN}$ CVD coated carbide tool. International Journal of Industrial Engineering Computations, 6(4), 539-552.

Benga, G. C., \& Abrao, A. M. (2003). Turning of hardened 100Cr6 bearing steel with ceramic and PCBN cutting tools. Journal of Materials Processing Technology, 143, 237-241. 
Çaydas, U. (2010). Machinability evaluation in hard turning of AISI 4340 steel with different cutting tools using statistical techniques. Proceedings of the Institution of Mechanical Engineers, 224(B7), 1043.

Ciftci, I. (2006). Machining of austenitic stainless steels using CVD multi-layer coated cemented carbide tools. Tribology International, 39(6), 565-569.

Dureja, J. S., Gupta, V. K., Sharma, V. S., \& Dogra, M. (2009). Design optimization of cutting conditions and analysis of their effect on tool wear and surface roughness during hard turning of AISI-H11 steel with a coated - mixed ceramic tool. Proceedings of the Institution of Mechanical Engineers, Part B: Journal of Engineering Manufacture, 223(11), 1441-1453.

Elbah, M., Yallese, M. A., Aouici, H., Mabrouki, T., \& Rigal, J. F. (2013). Comparative assessment of wiper and conventional ceramic tools on surface roughness in hard turning AISI 4140 steel. Measurement, 46(9), 3041-3056.

Fnides, B., Yallese, M. A., \& Aouici, H. (2008). Comportement à l'usure des céramiques de coupe $(\mathrm{Al} 2 \mathrm{O} 3+\mathrm{TiC}$ et $\mathrm{Al} 2 \mathrm{O} 3+\mathrm{SiC})$ en tournage des pièces trempées. Algerian Journal of Advanced Materials, 5, 121-124.

Garcia-Diaz, A., Hogg, G. L., \& Tari, F. G. (1981). Combining simulation and optimization to solve the multimachine interference problem. Simulation, 36(6), 193-201.

Horng, J. T., Liu, N. M., \& Chiang, K. T. (2008). Investigating the machinability evaluation of Hadfield steel in the hard turning with $\mathrm{Al} 2 \mathrm{O} 3 / \mathrm{TiC}$ mixed ceramic tool based on the response surface methodology. Journal of materials processing technology, 208(1), 532-541.

Kramer, B. M., \& Von Turkovich, B. F. (1986). A comprehensive tool wear model. CIRP AnnalsManufacturing Technology, 35(1), 67-70.

Kaddeche, M., Chaoui, K., \& Yallese, M. A. (2012). Cutting parameters effects on the machining of two high density polyethylene pipes resins: Cutting parameters effects on HDPE machining. Mechanics \& Industry, 13(5), 307-316.

Keblouti, O., Boulanouar, L., Azizi, M., \& Athmane, M. (2017). Modeling and multi-objective optimization of surface roughness and productivity in dry turning of AISI 52100 steel using (TiCN$\mathrm{TiN}$ ) coating cermet tools. International Journal of Industrial Engineering Computations, 8(1), 7184.

Meddour, I., Yallese, M. A., Khattabi, R., Elbah, M., \& Boulanouar, L. (2015). Investigation and modeling of cutting forces and surface roughness when hard turning of AISI 52100 steel with mixed ceramic tool: cutting conditions optimization. The International Journal of Advanced Manufacturing Technology, 77(5-8), 1387-1399.

Muthukrishnan, N., \& Davim, J. P. (2009). Optimization of machining parameters of Al/SiC-MMC with ANOVA and ANN analysis. Journal of Materials Processing Technology, 209(1), 225-232.

Neşeli, S., Yaldız, S., \& Türkeş, E. (2011). Optimization of tool geometry parameters for turning operations based on the response surface methodology. Measurement, 44(3), 580-587.

Smith, D. E. (1973). An empirical investigation of optimum-seeking in the computer simulation situation. Operations Research, 21(2), 475-497.

Singh, D., \& Rao, P. V. (2010). Flank wear prediction of ceramic tools in hard turning. The International Journal of Advanced Manufacturing Technology, 50(5-8), 479-493.

Singh, C. K., \& Vajpayee, S. (1980). Evaluation of flank wear on cutting tools. Wear, 62(2), 247-254.

Uvaraja, V. C., \& Natarajan, N. (2012). Optimization on friction and wear process parameters using Taguchi technique. International Journal of Engineering Technology, 2(4), 694-699.

Yallese, M. A., Boulanouar, L., \& Chaoui, K. (2004). Usinage de l'acier 100Cr6 trempé par un outil en nitrure de bore cubique. Mechanics \& Industry, 5(4), 355-368.

Yallese, M. A., Chaoui, K., Zeghib, N., Boulanouar, L., \& Rigal, J. F. (2009). Hard machining of hardened bearing steel using cubic boron nitride tool. Journal of Materials Processing Technology, 209(2), 1092-1104.

Zahia, H., Athmane, Y., Lakhdar, B., \& Tarek, M. (2015). On the application of response surface methodology for predicting and optimizing surface roughness and cutting forces in hard turning by PVD coated insert. International Journal of Industrial Engineering Computations, 6(2), 267-284. 
(C) 2018 by the authors; licensee Growing Science, Canada. This is an open access article distributed under the terms and conditions of the Creative Commons Attribution (CCBY) license (http://creativecommons.org/licenses/by/4.0/). 